\title{
Ausência paterna e sua repercussão no desenvolvimento da criança e do adolescente: um relato de caso
}

\author{
Mariana Eizirik* \\ David Simon Bergmann**
}

\section{INTRODUÇÃO}

A influência da ausência paterna durante o desenvolvimento de um filho é um tema rico e complexo. Concomitantemente aos diversos fatores individuais de cada caso, é indispensável examinar o impacto dessa ausência no desenvolvimento psicológico, intelectual e comportamental de uma criança ou adolescente.

Este tema desperta especial interesse nos dias de hoje, devido à modificação da estrutura familiar atual, em que se observa a crescente ausência do pai. As principais teorias do desenvolvimento se baseiam no modelo de família convencional, e, possivelmente, as novas configurações familiares repercutem nas relações interpessoais e intrapsíquicas, tornando este tema relevante.

Após uma revisão da literatura a respeito do tema, será apresentado o resumo de um

\footnotetext{
* Médica, Residente do Serviço de Psiquiatria do Hospital de Clínicas de Porto Alegre (HCPA).

** Médico Psiquiatra da Infância e Adolescência do Serviço de Psiquiatria da Infância e Adolescência do HCPA.
}

caso clínico em que essa questão e suas conseqüências permeiam a vida do paciente e, conseqüentemente, seu tratamento psicoterápico.

\section{REVISÃO TEÓRICA}

Segundo dados de Fishman' ${ }^{1}$, de 56 milhões de famílias norte-americanas, apenas 16,3\% são do tipo convencional, nuclear. Além disso, o número de crianças vivendo em uma família de apenas um genitor foi estimado entre 20 e $50 \%$ de todas as famílias, e destas famílias de genitor sozinho, a maioria provavelmente é chefiada por mulheres separadas ou divorciadas. O autor considera o grande número de famílias chefiadas por uma mãe uma reorganização significativa do sistema familiar norte-americano.

Montgomery ${ }^{2}$ fornece os seguintes dados: em classes sociais baixas, o número de crianças que vivem sem o pai biológico atinge mais de $40 \%$; das crianças nascidas na década de 90 , 55 a $60 \%$ passaram grande parte de sua vida afastadas dos pais biológicos; em 1960, o número de crianças vivendo só com a mãe era 
de 5 milhões, sendo que este número atinge 8 milhões em 1998, e mais de $50 \%$ dessas crianças não conhecem o pai biológico; dos pais ausentes, $26 \%$ vivem em estados diferentes das residências dos seus filhos. $O$ autor refere também que crianças com ausência do pai biológico têm duas vezes mais probabilidade de repetir o ano escolar, e que crianças que apresentam comportamento violento nas escolas têm 11 vezes mais chance de não viver na companhia do pai biológico do que crianças que não têm comportamento violento. Essas crianças, principalmente meninos, evidenciam maiores dificuldades nas provas finais e uma média mais baixa de leitura.

Dados do IBGE ${ }^{3}$ de 1999 mostram que $74 \%$ das famílias do Brasil são chefiadas por homens e $26 \%$ por mulheres. Na região Sul, $77,6 \%$ das famílias são chefiadas por homens e $22,4 \%$ por mulheres.

O estudo de Shinn ${ }^{4}$ revisou os efeitos da ausência paterna no desenvolvimento cognitivo das crianças. Concluiu que, em famílias sem a presença do pai ou nas quais os pais apresentavam pouca interação com seus filhos, havia maior associação com desempenhos pobres em testes cognitivos das crianças. Ansiedade e dificuldades financeiras poderiam contribuir para tais efeitos.

Svanum et al. ${ }^{5}$ também abordaram a associação entre ausência paterna e desempenho cognitivo em crianças entre 6 e 11 anos. Os resultados levaram às conclusões de que a ausência paterna, utilizada como uma variável índice, representando processos familiares e psicossociais subjacentes, é inconsistente e até fracamente relacionada com o desenvolvimento cognitivo em crianças. Também apontam que diferenças atribuídas à ausência paterna podem ser decorrentes, em grande parte dos casos, do nível socioeconômico das famílias.

Freud $^{6}$, em seu trabalho Leonardo da Vinci e uma lembrança da sua infância, diz: "na maioria dos seres humanos, tanto hoje como nos tempos primitivos, a necessidade de se apoiar numa autoridade de qualquer espécie é tão imperativa que seu mundo desmorona se essa autoridade é ameaçada".

Rohde et al. ${ }^{7}$ concluem que a função paterna é fundamental para o desenvolvimento do bebê. Segundo os autores, tal função é dinâmica, já que o pai representa um sustentáculo afetivo para a mãe interagir com seu bebê e também, ainda nos primeiros anos da criança, deve funcionar como um fator de divisão da relação simbiótica mãe-bebê.
Muza $^{8}$ contribui com este tema, dizendo que "o pai aparece como o terceiro imprescindível para que a criança elabore a perda da relação inicial com a mãe", sendo que "a criança necessita do pai para desprender-se da mãe e, ao mesmo tempo, também necessita de um pai e de uma mãe para satisfazer, por identificação, sua bissexualidade". Prossegue afirmando que "o pai passa a representar um princípio de realidade e de ordem na família, e a criança sente que ela não é mais a única a compartilhar a atenção da mãe".

Segundo Ferrari ${ }^{9}$, "a presença de ambos os pais é que permite à criança viver de forma mais natural os processos de identificação e diferenciação", e quando um falta, ocorre sobrecarga no papel do outro, gerando um desequilíbrio que pode causar prejuízo na personalidade do filho. O autor diz que, em muitos casos, ocorre uma "superpresença da mãe, anulando a personalidade do filho ou filha". Comentando o complexo de Édipo no menino, diz que, "para o menino, a ausência do pai significa que nada se interpõe entre ele e sua mãe, o objeto desejado, que é toda sua. Mas esta mãe tão amada também começa a dar limites, e se inicia a guerra". Considera que a entrada na escola possa facilitar o processo nesse sentido, com o surgimento de outros objetos, com os quais o menino poderá competir e se identificar, mas pensa que nem sempre essas compensações tardias poderão equilibrar a situação internalizada.

Além do papel crucial que o pai exerce na triangulação pai-mãe-filho, como já visto, Muza ${ }^{8}$ cita o outro momento em que o papel paterno é crucial para o desenvolvimento dos filhos: a entrada na adolescência, quando "a maturação genital obriga a criança a definir o seu papel na procriação".

O impacto da ausência do pai na adolescência é estudado no trabalho de Jones et al. ${ }^{10}$. Os autores compararam a separação psicológica e separação-individuação dos pais em dois grupos: 25 meninos adolescentes que viviam com seus dois pais biológicos e 25 meninos adolescentes que viviam apenas com suas mães biológicas. Os resultados mostraram que os meninos dos dois grupos não diferiram nas medidas de separação-individuação, e que a qualidade da relação mãe-filho mediou muitas das manifestações de separação-individuação avaliadas. Tais resultados enfatizam a importância da qualidade da relação do filho com sua mãe e com seu pai como um mediador de muitas dimensões do processo de separação-individuação. 
Segundo Muza ${ }^{8}$, crianças que não convivem com o pai acabam tendo problemas de identificação sexual, dificuldades de reconhecer limites e de aprender regras de convivência social. Isso mostraria a "dificuldade de internalização de um pai simbólico, capaz de representar a instância moral do indivíduo". Tal falta pode se manifestar de diversas maneiras, entre elas uma maior propensão para 0 envolvimento com a delinqüência.

$O$ estudo de Mason et al. ${ }^{11}$ aborda os problemas de comportamento associados ao efeito dos pares e ao papel moderador da ausência paterna e da relação mãe-filho. O comportamento dos pares e a ausência paterna vêm sendo associados com maiores índices de distúrbios do comportamento em adolescentes. Pesquisas mostram que a ausência paterna geralmente tem um impacto negativo em crianças e adolescentes, sendo que estes estariam em maior risco para desenvolver problemas de comportamento. O estudo examinou o impacto dos pares, a ausência paterna e a relação mãe-filho em 112 adolescentes afro-americanos com problemas de comportamento. Um modelo moderador foi usado para testar a hipótese de que a ausência do pai (ou equivalente) exacerbaria o impacto negativo de pares com distúrbios de comportamento, enquanto uma relação mãefilho positiva seria um fator protetor contra esse risco e quanto à ausência paterna. O modelo moderador sugeriu que a ausência paterna ou de equivalente aumentou o impacto negativo de pares com problema comportamental, enquanto uma relação positiva mãe-adolescente atenuou este risco. Uma forte relação mãe-adolescente também mostrou proteger adolescentes de famílias sem pai do risco de distúrbios comportamentais associados ao envolvimento com pares com tais problemas.

Paschall et al. ${ }^{12}$ estudaram os efeitos de ausência paterna, cuidado parental e associação com pares delinqüentes entre adolescentes afroamericanos com comportamento delinqüente. Os autores reportam que os achados de estudos relacionados ao tema são mistos e inconclusivos e que há grande preocupação a respeito da ausência paterna em famílias afro-americanas em relação ao efeito negativo que isso pode causar no desenvolvimento desses meninos. Nesse estudo, a ausência paterna não foi associada com comportamento delinqüente dos filhos e também não foi moderadora da relação entre associação com pares delinqüentes e comportamento delinqüente dos filhos. Mas o efeito negativo do fator socioeconômico no comportamento delinqüente foi mais freqüente em famílias com pai ausente.

Pfiffneret al. ${ }^{13}$ estudaram a associação entre ausência paterna e características antisociais familiares. Os resultados mostram que famílias com o pai morando em casa tiveram menos sintomas anti-sociais na mãe, no pai e na criança do que famílias sem o pai. Características anti-sociais foram maiores quando os pais não foram encontrados para participação no estudo. Os autores concluem que comportamento anti-social em qualquer membro da família é mais provável se o pai é ausente ou não-participativo.

Um interessante estudo de Jensen et al. ${ }^{14}$ mostrou que a ausência paterna dentro de condições rotineiras e em famílias relativamente saudáveis pode não exercer efeitos independentes significativos. Tais efeitos estariam mais associados à psicopatologia materna e a estressores ambientais. Foram avaliadas 213 crianças, filhas de militares ausentes durante o ano anterior à pesquisa. Crianças com o pai ausente por 1 mês ou mais mostraram significativamente mais depressão e ansiedade auto-referidas, sendo que este resultado não foi significativo após o controle de estressores ambientais e psicopatologia materna.

Tais achados chamam a atenção para um dado importante: a influência do comportamento materno nas situações de ausência paterna (e de como a mãe reage a essa ausência). Podese dizer que os efeitos da ausência paterna sobre a criança são mediados pela interação da mãe com o filho e pelos recursos emocionais da mãe. O mesmo se pode dizer da participação dos fatores ambientais e da família como um todo, que cercam a criança.

Ferrari ${ }^{9}$ contribui muito para o estudo deste assunto. Afirma que "há uma necessidade inata de filiação nos seres humanos, o que não é diferente com os filhos de mães sozinhas". O autor também diz que os filhos "têm a necessidade de saber por que seu pai partiu e de escutar isso da boca deste, e não através da interpretação da mãe".

Ferrari $^{9}$ aborda a questão dos pais substitutos, comentando que estes também podem se afastar, deixando a criança novamente com a sensação de abandono. A situação se torna mais complicada neste aspecto quando a mãe tem relacionamentos instáveis e rápidos. Além disso, há a ambivalência da criança em aceitar um substituto para o pai biológico. Outro aspecto importante é o da situação de um término de 
relacionamento da mãe, quando o filho pode sentir como se fosse mais uma vez culpado por isso, aumentando sua sensação de orfandade ${ }^{9}$.

Este mesmo autor ${ }^{9}$ comenta que qualquer busca do pai pode parecer ao filho como uma traição à mãe, e também que momentos críticos da vida do filho (casamento ou nascimento de um filho, por exemplo) tornam mais forte o desejo de conhecer o genitor ausente, como "uma necessidade de fechar sua história". Diz que "por mais que as crianças não digam nada, o vazio está presente e trabalha".

Este vazio, segundo Ferrari ${ }^{9}$, é formado pela noção das crianças de não serem amadas pelo genitor que está ausente, com uma grande desvalorização de si mesmas em conseqüência disso. Além dessa autodesvalorização, ocorrem os sentimentos de culpa "por ser uma criança má, por haver provocado a separação, por ter nascido". A criança pensa ser má por ter sido deixada. O autor coloca que isso "pode gerar reações variadas, desde tristeza e melancolia até agressividade e violência". E prossegue dizendo que "os tímidos e temerosos do exterior se fecham em si mesmos, e os extrovertidos e temerosos do interior de sua história se vingam no mundo com condutas anti-sociais".

A escola, como foi dito por Ferrari ${ }^{9}$, tem a função de romper o cordão umbilical, sendo o momento em que a criança entra em maior contato com o mundo real. Como já mencionado pelo mesmo autor, não se sabe se já não seria tarde para isso, além de haver situações que mostram que a escola não seria suficiente para produzir a separação necessária. Segundo o autor, "os fracassos escolares e os problemas de aprendizado e de relacionamento com os outros têm como base, na maioria dos casos, situações familiares". Ferrari diz que também pode ocorrer o inverso: para agradar a mãe, com o temor de ser abandonado por esta, o filho se torna um ótimo aluno, sendo que tal "temor de abandono pela mãe pode não durar toda a vida escolar da criança". Diz que "essa identificação total com a mãe pode saturar-se com a chegada da puberdade ou da adolescência e, quebrado o encanto, iniciam-se os problemas".

Em síntese, a literatura consultada evidencia as modificações na estrutura da família contemporânea, os efeitos negativos da ausência do pai e as repercussões decorrentes dessa ausência tanto nos aspectos comportamentais quanto nas vivências emocionais relacionadas com o complexo de Édipo, produzindo variadas expressões de conflitos, defesas e sentimentos de culpa nos filhos sem pai.
Uma ilustração clínica pode exemplificar mais vivamente vários desses aspectos.

\section{CASO CLÍNICO}

João é um adolescente de 16 anos. Foi encaminhado para tratamento psicoterápico por dificuldades escolares. Foi reprovado uma vez na 6aㅗ série e duas vezes na $8^{\underline{a}}$ série. O paciente diz que não gosta de estudar e que, por isso, não consegue ter bons resultados acadêmicos. $O$ diagnóstico de transtorno de déficit de atenção e hiperatividade foi excluído, pois o paciente não tem dificuldade em prestar atenção a detalhes ou fixar sua atenção nas atividades, nem apresenta outros critérios para este transtorno, e sim falta de estímulo, de interesse em estudar, principalmente quando está em casa.

João foi criado pela mãe, pela avó materna e por um tio materno. Não conhece seu pai. Sabe que este tem outros filhos e afirma nunca ter tido interesse em conhecê-lo. Comenta que a mãe já sugeriu apresentá-lo ao pai, mas que não quis. Atualmente, mora com a mãe e a avó, que tem uma doença degenerativa crônica, diagnosticada há 2 anos, estando muito sintomática. O paciente tem sido responsável por vários cuidados com a avó, como lidar com seu dinheiro e com precauções quanto à sua integridade física enquanto estão sozinhos em casa. Tem sofrido muito com essa situação, referindo que está perdendo alguém importante novamente, o que o faz sentir-se cada vez mais só.

A mãe e a avó têm uma relação difícil. Brigam constantemente, e o paciente se sente "no meio" das duas, exercendo um papel que era de seu tio. Sabe que é algo pesado para ele e tem se sentido cansado, com muita vontade de ficar fora de casa ou trancado em seu quarto, para não ouvir as brigas.

A mãe de João sempre trabalhou bastante, ficando afastada do convívio doméstico. Ele conta ter sido criado basicamente pela avó e pelo tio, que faleceu quando o paciente tinha 6 anos. Não fala muito sobre este fato, mas, ao surgir o assunto na sessão, João não se sente à vontade, pelo provável sofrimento que ainda desperta. Quando a morte do tio é abordada, geralmente é minimizada pelo paciente, que costuma dizer que "já faz tempo" e "não tem nada a ver com seus problemas atuais".

Sua relação com a mãe é difícil. Queixa-se com freqüência de que esta é muito preocupada e controladora, que se interessa apenas por seus estudos. Nota que ela o compara com alguns familiares, que são melhor sucedidos nessa área, e sente que a decepciona, não 
suprindo suas expectativas. Repete constantemente que não gosta de estudar, que é "vagabundo" e não tem grandes ambições para o futuro. Pretende terminar o ensino médio porque "sabe que precisa", mas diz que não pretende freqüentar uma universidade.

Tem um grupo de amigos que o acompanha desde a infância, com quem sai à noite, vai a festas. Não tem namorada. Sente-se constrangido ao falar de namoro durante as sessões. Nesses momentos, compara as relações com a terapeuta e com sua mãe: as duas ficam "perguntando tudo".

Nega uso de drogas. Bebe álcool apenas em festas, geralmente pouco, apenas para "se soltar e aproveitar melhor". Costumava se envolver facilmente em brigas físicas, sem crítica da sua possível participação no desencadear destas. Após algumas sessões em que este assunto foi discutido, deu-se conta de que provocava as brigas e não conseguia deixar de participar. Concluiu que brigar e se machucar, como vinha ocorrendo, poderia ser um dos meios conhecidos para chamar a atenção de sua mãe, já que pensava que esta só ficava atenta e preocupada quando ele estava envolvido em problemas. Não brigou mais após essa percepção, tentando prestar atenção em seu comportamento e evitando novos confrontos.

No início do tratamento, os silêncios eram longos e freqüentes. João parecia desconfortável, sem saber o que deveria dizer e fazer com o silêncio, que o constrangia. No entanto, raramente faltava e demonstrava esforço para chegar pontualmente à sessão. Com o passar do tempo, o vínculo terapêutico foi sendo formado, e ele deixou aparecer mais claramente o sofrimento e o sentimento de solidão que o acompanhavam.

A solidão aparece como um ponto muito importante em sua vida. Foi um menino sem pai durante todo o seu desenvolvimento, sendo que houve um investimento no tio como figura paterna substituta, com o aumento da sensação de vazio após a perda deste.

João resistiu por um longo período em tocar no assunto do pai. Quando surgia, dava respostas curtas, minimizava a importância do tema na sua vida e evitava expressar qualquer tipo de sentimento. Repetiu inúmeras vezes que a mãe foi como um pai, que lhe deu tudo o que podia e que nunca precisou de um pai; este não fez nenhuma falta.

O paciente, com o aumento da confiança no tratamento e com a descoberta do seu benefício, começou a falar mais durante as sessões. Em um desses momentos, conseguiu expressar alguns sentimentos em relação à ausência do pai, assunto que praticamente não havia mencionado durante meses de tratamento:

$P$ - A minha avó está mal, eu sinto falta dela.

$T$ - É difícil porque estás perdendo ela e assistindo a isso, não é?

$P$ - É. Eu, que já era sozinho, agora, sem ela, vou ficar mais ainda. Completamente sozinho. Tem a mãe, claro. Vamos ser só nós dois agora. Quando o meu tio morreu, foi brabo, e agora a minha avó. Mas eu já sou bem grandinho.

$T$ - Grandinho para quê?

$P$ - Para ficar falando, me queixando. Não tem nada a ver, já sou grandinho para me virar.

$T$ - E te vira, mas mesmo quem é grande sofre, fica triste.

$P$ - Eu nunca tive uma família. Tenho inveja dos meus amigos que têm.

$T$ - Família com pai, com mãe.

$P$ - Eu nunca tive pai. Mas a minha mãe sempre se virou, me deu tudo. Eu nunca precisei de um pai. Ela disse que sempre quis ter um filho, tudo bem, foi uma opção dela.

$T$ - E se tu sentes por esta falta de pai? Acho que isso te causa sofrimento.

$P$ - Causa sim. A minha mãe me perguntou uma vez se eu queria conhecer ele, e eu disse que não. Para quê? Ele nunca me deu nada, nunca me procurou.

T-Acho que é um assunto importante para ti, que tens dificuldade em tocar.

$P$ - Não sei se é tão importante assim. Agora, eu não preciso mais de pai. Nem queria ele como pai. (...) Eu tenho raiva, porque nunca me procurou, puxa vida, nem para saber quem eu sou, como eu sou. Eu acho que iria partir para cima dele se eu o conhecesse. (...) Eu já sonhei com ele. Sonhei que ele me procurava e eu botava a boca nele, perguntava por que ele tinha feito isso comigo.

Na sessão seguinte, o paciente disse que não lembrava sobre o que havia falado na última sessão. Após a terapeuta perguntar se ele realmente não lembrava, falou que estavam falando sobre o pai.

$P$ - Ah, estávamos falando sobre o meu pai, sobre ele não ter me procurado, essas coisas. Se ele me procurasse hoje, eu até falaria com ele.

$T$ - No sonho que me contaste, ele te procurava e brigavas com ele. 
$P$ - Sonhei isso? Nem me lembrava. Pois é, mas hoje eu até falaria com ele. Mas nunca apareceu mesmo.

$T$ - E tu, já pensaste em procurá-lo?

$P$ - Não. Não vou procurar. [silêncio] Eu não falo essas coisas para a minha mãe, para ninguém.

$T$ - Mas estás falando para mim.

$P$ - Pois é. Nunca falei muito de mim, nem conversei sobre as minhas coisas.

Poder falar a respeito de um assunto reprimido por tanto tempo trouxe alívio ao paciente, entre outros motivos, porque viu que poderia ter o direito de sofrer com essa falta e expressá-la, sendo aceito. Isso trouxe maior liberdade ao tratamento, abrindo espaço para a análise de outros conflitos com maior facilidade, aumentando o vínculo terapêutico.

\section{CONSIDERAÇÕES FINAIS}

A partir do caso clínico relatado e da revisão bibliográfica, pode-se afirmar que o assunto em questão é repleto de possibilidades de estudo e reflexão.

Fica evidenciado que a ausência paterna tem potencial para gerar conflitos no desenvolvimento psicológico da criança. A influência da ausência paterna no desenvolvimento cognitivo e em distúrbios do comportamento, a partir dos dados citados, permanece em aberto, com dados apontando para a influência negativa da ausência paterna nessas questões e outros apontando para uma ausência de influência.

No caso clínico ilustrado, o mau desempenho escolar do paciente é um fator marcante de sua vida passada e atual. Teve três repetições na escola e segue com dificuldades nessa área. Foi levantada a hipótese de que sair-se mal na escola seria a maneira encontrada por João para chamar a atenção da mãe, já que pensa que esta só se preocupa com ele desta forma. Ou seja, ter um bom desempenho facilitaria o caminho para ser "deixado de lado" pela mãe, que não teria motivos para pensar nele. Quanto à questão de transtornos de conduta, não pensamos ser este um problema em relação ao paciente. Seu envolvimento freqüente em brigas também parecia estar a serviço de sua necessidade de ser cuidado, tentando despertar a preocupação materna. Além disso, tal comportamento foi bastante reduzido após a compreensão de sua função por parte do paciente.

A ausência do pai era um tema reprimido por João. A relação com a terapeuta e, possivelmente, a aliança terapêutica estabelecida permitiu a ele que trouxesse à tona este tema tão doloroso, em especial seu ódio contra o pai: "acho que iria partir para cima dele se eu o conhecesse (...), eu botava a boca nele, perguntava por que ele tinha feito isso comigo". Há, talvez, algo de ambíguo nessas expressões, podendo demonstrar ambivalência. "Partir para cima", "botar a boca", "perguntar por que" podem sugerir expressões agressivas, mas, ao mesmo tempo, um desejo de contato, de aproximação afetiva.

A expressão desses sentimentos ambivalentes na psicoterapia é um elemento que pode permitir a melhor elaboração desse luto, que está sendo revivido com a perda da avó (como foi com a do tio).

Um fator essencial a ser levado em consideração nas situações de ausência do pai no desenvolvimento da criança é o papel materno. Devem ser considerados a presença de psicopatologia materna, os recursos emocionais desta e o tipo de relacionamento que existe entre a mãe e o filho. Desse relacionamento pode surgir uma maior ou menor predisposição para os conflitos associados à falta do pai, ou seja, tal relação seria como uma mediadora das repercussões dessa ausência na vida emocional da criança. Deve-se considerar também a participação do ambiente familiar, social e econômico, os quais também podem exercer influência no desenvolvimento da criança e em como ela lida com a ausência do pai.

No caso clínico discutido, observamos que a mãe de João, com todas as suas possíveis limitações emocionais e de disponibilidade de tempo, com a ajuda da avó e do tio, conseguiu exercer bem seu papel de cuidadora e de educadora. Isso fica evidente pelos traços adaptativos da personalidade do paciente e por seus valores éticos. Mostra-se uma pessoa interessada em melhorar, estabelecendo um bom vínculo terapêutico, além de demonstrar respeito pelos outros e preocupação com a família. Isso é conseqüência, provavelmente, de um ambiente com um grau suficiente de afeto e continência, apesar da ausência do pai. Esta possivelmente foi uma das responsáveis pela baixa auto-estima de João, que pôde ser observada em situações em que se definiu como sendo incapaz de atingir seus objetivos, de obter bens materiais ou status social, "ser alguém na vida".

É necessário um maior número de estudos para podermos aprofundar nosso conhecimento e, conseqüentemente, ter mais possibilidades de compreender e ajudar nossos pacientes. 


\section{REFERÊNCIAS BIBLIOGRÁFICAS}

1. Fishman HC. Uma família de progenitor sozinho: um sistema organizado desorganizado. In: Fishman HC Tratando adolescentes com problemas: uma abordagem da terapia familiar. Porto Alegre: Artes Médicas; 1996. p.225-39.

2. Montogmery M. Breves comentários. In: Silveira P Exercício da paternidade. Porto Alegre: Artes Médicas 1998. p.113-8.

3. Instituto Brasileiro de Geografia e Estatística (IBGE) Disponível em www.ibge.gov.br. Acessado $1^{\circ}$ ago 2004.

4. Shinn M. Father absence and children's cognitive development. Psychol Bull 1978;85(2):295-324.

5. Svanum S, Bringle RG, McLaughlin JE. Father absence and cognitive performance in a large sample of six- to eleven-year-old children. Child Dev 1982;53(1):136-43.

6. Freud S (1910). Leonardo da Vinci e uma lembrança da sua infância. In: Freud S. Obras psicológicas completas. Rio de Janeiro: Imago; 1970. vol.XI, p.59-124.

7. Rohde LA, Wolf AL, Couto AF, Shansis DM, Shansis FM, Cunha GB, et al. A função paterna no desenvolvimento do bebê. Rev Psiquiatr RS 1991;13(3):127-35.

8. Muza GM. Da proteção generosa à vítima do vazio. In Silveira P. Exercício da paternidade. Porto Alegre: Artes Médicas; 1998. p.143-50.

9. Ferrari JL. Por que es importante el padre? In: Ferrai JL. Ser padres en el tercer milenio. Mendoza: Ediciones de Canto Rodado; 1999. p.91-117.

10. Jones KA, Kramer TL, Armitage T, Williams K. The impact of father absence on adolescent separation-individuation. Genet Soc Gen Psychol Monogr 2003;129(1):73-95.

11. Mason CA, Cauce AM, Gonzales N, Hiraga Y. Adolescent problem behavior: the effect of peers and the moderating role of father absence and the mother-child relationship. Am J Community Psychol 1994;22(6):723-43.

12. Paschall MJ, Ringwalt CL, Flewelling RL. Effects of parenting, father absence, and affiliation with delinquent peers on delinquent behavior among African-American male adolescents. Adolescence 2003;38(149):15-34.

13. Pfiffner LJ, McBurnett K, Rathouz PJ. Father absence and familial antisocial characteristics. J Abnorm Child Psychol 2001;29(5):357-67.

14. Jensen PS, Grogan D, Xenakis SN, Bain MW. Father absence: effects on child and maternal psychopathology. J Am Acad Child Adolesc Psychiatry 1989;28(2):171-5.

\section{RESUMO}

A ausência paterna durante o desenvolvimento da criança e do adolescente é um tema complexo, com grandes possibilidades para estudo. É feita uma revisão da literatura a respeito do tema. Discute-se a influência da ausência paterna no desenvolvimento emocional, cognitivo e comportamental da criança e do adolescente. A participação da mãe nessas situações, do ambiente familiar como um todo e dos fatores sociais e econômicos como mediadores das conseqüências da ausência do pai na vida da criança são levados em consideração. Os autores apresentam o resumo de um caso clínico em que a ausência do pai é um ponto importante da vida do paciente. Ao longo do atendimento psicoterápico, foram surgindo as percepções e emoções do paciente associadas à ausência do pai.

Descritores: Ausência paterna, criança, adolescente, psicoterapia.

\section{ABSTRACT}

Father absence during child and adolescent development is a complex theme, with several study possibilities. The authors of the present study review the literature on the theme. The influence of father absence on emotional, cognitive and behavioral development is discussed. In these situations, other participation, family environment and social and economic factors are taken into account. The authors present a clinical case in which father absence was an important aspect in the patient's life. Psychotherapy allowed for the patient's emotions and perceptions associated with father absence to appear.

Keywords: Father absence, child, adolescent, psychotherapy.

Title: Father absence and its influence on child and adolescent development: a case report

\section{RESUMEN}

La ausencia del padre durante el desarrollo del niño y del adolescente es un tema complejo, con muchas posibilidades de estudio. Los autores revisan la literatura sobre el tema, y discuten la influencia de la ausencia del padre en el desarrollo emocional, cognitivo y comportamental. Se toman en cuenta la participación de la madre en estas situaciones, el ambiente familiar en su totalidad y los factores sociales y económicos como mediadores de las consecuencias de la ausencia del padre en la vida del niño. Los autores presentan el resumen de un caso clínico, en el que la ausencia del padre fue un importante hecho en la vida del paciente. $A$ lo largo de la psicoterapia, aparecieron progresivamente las emociones y percepciones del paciente asociadas a la ausencia del padre.

Palabras clave: Ausencia del padre, niño, adolescente, psicoterapia.

Título: La ausencia del padre y su repercusión en el desarrollo del niño y del adolescente: un estudio de caso

Correspondência:

Mariana Eizirik

Rua Visconde do Rio Branco, 708 - Bairro Floresta

CEP 9220-230 - Porto Alegre - RS

Fone: (51) 3222-0840/9808-0611

E-mail: marianae.ez@terra.com.br

Copyright (C) Revista de Psiquiatria do Rio Grande do Sul - SPRS 